\title{
Placebos in Medicine: Knowledge, Beliefs, and Patterns of Use
}

\author{
Amir Raz*†, Eugene Raikhel†, and Ran D. Anbar $\dagger$
}

This special collection of papers on the topic of placebos features diverse contributions from leading researchers. We are privileged to benefit from the perspectives of John Kihlstrom, Elizabeth Loftus and James Fries, Pesach Lichtenberg, and Irving Kirsch. In this commentary we contextualize the different accounts within an overarching whole.

While most contributors to this MJM Focus Reviews section are non-physicians, placebo research is a field of great importance to any health care professional. Although scholarly definitions abound (1), most practitioners loosely regard the placebo effect as any treatment that improves a symptom or disease but lacks specific effectiveness for the condition being treated (2). As we demonstrate below, the placebo effect is both powerful and inherent in any clinical interaction (3). In addition, the patient-practitioner relationship is a significant component of the psychosocial context of treatment, because health care workers communicate important information to the patient through their words, attitudes and demeanor (4). Use of placebos, therefore, presents a didactic, philosophical, ethical, and practical challenge for most physicians.

\section{PLACEBOS AND PSYCHOSOCIAL FACTORS IN MEDICINE}

Placebos exemplify the link between psychosocial factors and physiological processes. They bind psychology to the techniques of neuroscience and

\footnotetext{
*To whom correspondence should be addressed:

Amir Raz, Ph.D., ABPH

McGill-JGH-ICFP-MNI Canada Research Chair

4333 Cote Ste Catherine Rd.

Montreal, Quebec H3T 1E4

Canada

Tel: 514-340-8210 ; Fax: 514-340-8124

E-mail: amir.raz@mcgill.ca

$\dagger$ McGill University

†SUNY Upstate Medical University
}

medicine $(5,6)$ and are beginning to connect physiology to the social sciences (7-9). Outlining the current inadequacies of medicoscientific reductionism in relation to the relative merits of social science, Kihlstrom's piece nicely complements that of Raz \& Guindi on "Placebos and Medical Education." Individuals under the influence of a charismatic authority can have bodily experiences that many professionals would consider "all in the head." Such phenomena form an important element of many of the world's healing traditions, ranging from shamanism and possession cults to Christian healing practices $(10,11)$. The King's Touch (KT), for example, refers to a medieval belief that illness could be cured by the touch of a divinely anointed monarch (12). Following the introduction of the practice to Western Europe by Edward the Confessor, kings in both France and England healed patients by the laying on of hands, with specific diseases (e.g., tuberculosis of the neck) reportedly being especially amenable to their touch (13). By the 17 th century, KT had extended well beyond the throne. Irish healer Valentine Greatrakes - aka "The Stroker" - was able to amass thousands of clients, with "his barns and outhouses crammed with innumerable specimens of suffering humanity" (14). While Greatrakes probably practiced a layman's form of psychotherapy that had previously been restricted to members of the ruling class (15), modern science speciously dismisses KT as preposterous. One Nobel Laureate, for example, claimed that chicken soup might be a more credible source of healing than KT because ingesting soup may have chemical effects while it seems impossible for the symbolic act of KT to exert influence on the body (16). However, suggestion can indeed bring about veridical physiological changes (1719).

Kihlstrom's prominent investigations into hypnosis, cognitive, clinical and personality psychology, and health research put him in a unique position to comment 
on the social science of placebos. His piece is the backbone of this special issue and establishes the milieu for the other papers.

\section{PLACEBOS IN MEDICAL PRACTICE}

While commonly used by physicians in the clinical setting prior to the 19th century, placebos fell out of favor with the emergence of modern medicine (20). Over the past decade, however, our knowledge of the neural correlates of placebo mechanisms has greatly increased, rekindling the placebo "flame" anew (21). While bioethical issues shroud the use of placebos in evidence-based medicine (2), some clinicians, mostly academic physicians, appreciate the relative merits of placebos and capitalize on their mind-body therapeutics (22).

In his piece, Lichtenberg provides a glimpse into the use of placebos in clinical settings. Many readers may repudiate the use of inert treatments outside of research, but such practices abound in medical care. Placebos have been around for many years and are likely to persist at least a while longer. Modern physicians will do well to appreciate their foibles and virtues.

Studies, including recent research efforts, provide evidence for the use of placebos in clinical contexts. A survey of head nurses in a Connecticut health district evaluated the status of placebos within the hospital setting and found that $44 \%$ of respondents reported that placebos were currently being used in their unit or that placebos had been used within the past six months (23). In another study aiming to determine knowledge and patterns of placebo use, researchers sent surveys to house officers and registered nurses (RNs) working in two university teaching hospitals in the U.S. (24). Seventy-eight percent of physicians who responded had ordered at least one placebo as a painkiller, while $82 \%$ of RNs had administered at least one placebo as a painkiller. In Canada, researchers surveyed doctors and nurses from the Victoria General Hospital in Halifax to assess their knowledge of and attitudes towards placebo, as well as their patterns of placebo use (25). Eighty percent of both the RNs and physicians reported having administered a placebo during their time at the hospital, with $91 \%$ of the placebos consisting of saline injections. In yet another study examining the frequency of placebo use within nursing clinical practice, researchers found that among 263 respondents, 178 $(68 \%)$ had administered a placebo to patients; however, only $12 \%$ had done so within the last year (26). In Denmark, a survey of 772 physicians found that among the 503 respondents, $86 \%$ of the general practitioners, $54 \%$ of the hospital doctors, and $41 \%$ of the private specialists reported using placebo interventions at least once within the last year (27). In a separate study probing the frequency of placebo administration among physicians and nurses in Israel, researchers found that 53 out of 89 respondents reported prescribing placebos, 33 of whom said they had prescribed them as often as once a month (28). Finally, a more recent study found that academic physicians in the Chicago area used placebos in everyday clinical practice (22). Forty five percent of these physicians surveyed reported administering placebos, though $96 \%$ believed that placebos have a therapeutic effect. Despite this evidence that physicians are prescribing placebos (22, 28 ), no specific protocol currently governs their clinical use.

Following up on recently published efforts $(22,27$, 28), we have put together a web-based questionnaire aiming to survey knowledge, beliefs, patterns of use, and attitudes among health care professionals concerning placebos. With this tool we hope to probe the way clinicians and medical students construe placebos and the extent to which these individuals use placebos in clinical practice. We expect that our findings will elucidate the prevalence and impact of placebos in medical practice. We encourage you to visit http://tinyurl.com/PlaceboSurvey and fill out a short anonymous questionnaire to assess beliefs, patterns of use, and attitudes concerning placebos. We hope to provide results of our survey before long.

\section{PLACEBOS AND THE CONSENT FORM}

Even if clinical use of placebos remains relatively widespread, a dramatic change over the past decades makes this practice increasingly difficult to discuss or acknowledge. With the rapid growth of legal and administrative regulations affecting medical practice and decision-making since the $1960 \mathrm{~s}$, as well as the enshrinement of patient autonomy as an ethical norm in medicine, the therapeutic use of placebos has become something of a dirty secret $(29,30)$. At the heart of this bureaucratic management of clinical ethics is the idea of informed consent. Early proponents of clinical and research ethics questioned whether complete consent was ever realizable, and argued that responsible clinicians and investigators represent a "far more dependable safeguard than consent" (31-33). However, the recent tendency is to ensure consent by exposing patients to ever-more compendious accounts of possible side-effects and risks, however minor or unlikely. This trend takes on a particularly extreme form in the United States, where a notably litigious culture fosters a strong risk-aversion tactic among institutions providing medical care. Thus, the consent form has turned into the virtual opposite of the placebo.

If consent forms represent the apogee of transparency and rational choice, placebos seem to be an apparently 
inevitable prelude to deceit. As Loftus and Fries argue, however, even with increased reliance on bureaucratic tools such as consent forms, the purview of suggestion and expectation - core placebo components - continues to thrive. In fact, the insistence on full disclosure introduces a new, generally unappreciated variant of suggestion into our midst. In their unpublished pilot study, Loftus and Fries show that patients who sign consent forms describing side effects (some of which are invented by the researchers) do in fact experience those side effects in response to placebo. Such negative responses (i.e., "nocebo effects") overlap with certain placebo phenomena $(34,35)$. Moreover, that the act of reading and signing a form is a source of suggestion underscores the range of factors which can produce physiological effects without physical or chemical intervention.

In the minds of many contemporary practitioners who thrive on the ideals of patient autonomy and selfrealization, placebos belong to an era when paternalism and beneficence characterized the therapeutic relationship. Two opposing stances, however, seem to guide even the beneficial effects of modern placebos: a passive current of "being cared for" and an active one of "caring for oneself" (36). It is likely that both have physiological effects. After all, mere observation often induces behavioral changes in patients, even in the absence of active clinical interventions - the "Hawthorne effect" (37).

\section{SHOULD WE DEVELOP PLACEBOS FOR MEDICAL PRACTICE?}

Sometimes, when clinical trials demonstrate that an experimental treatment is comparable to a placebo, clinicians conclude that the treatment is unsuitable for prescription. Such a conclusion, however, is incongruous with the notion that receiving nothing is appropriate or preferable. For example, in several randomized double-blind trials, non-prescription cough suppressants and expectorants have failed to show increased effectiveness over placebo (38). Many pediatricians refuse to recommend over-the-counter cough therapy because they think it is ineffective and potentially harmful (39). Such practice, however, disregards the placebo effect. In other words, nonprescription cough therapy probably is helpful for some individuals because of its placebo effect. For this reason, the medical community may wish to consider identifying therapies that work as a result of placebos. Such interventions should have minimal side-effects and be inexpensive; yet should be unusual and costly enough to raise patients' expectations regarding effectiveness (40).

On the other hand, some clinicians continue to prescribe certain medications even if their effects are comparable to placebos. Typically, the reluctance to stop prescribing medication is due to force of habit, a desire to please the patient, or the belief that anecdotal experience provides sufficient evidence for its efficacy. For example, as Kirsch reports in this issue, despite ample evidence that anti-depressants provide scant benefit beyond a placebo effect, many clinicians insist on continuing their use.

\section{PLACEBOS AND MEDICAL EDUCATION}

Western medicine follows largely in the footsteps of Descartes, whose mind-body dualism allowed physicians to treat the body without worrying about the potential effect of their interventions on the soul and made the practice of medicine more acceptable to theologians of the time (41). Modern students often learn to construe the body as an isolated entity, unaffected by the mind or social environment (42). Thus our medical system continues to operate from the point of view that we can understand and treat disease in biological terms, largely neglecting the effects of the mind on the body or vice versa.

Even if some medical students and physicians acknowledge that psychology might matter to clinical practice, few view psychology as a science on par with biology. Instead, they consider psychology and the other social sciences to be "soft" while regarding themselves as operating in the domain of "real," hard science (43). Whereas a reduction from biology to chemistry to physics may seem viable to many individuals, a reduction from psychology is knottier. Nonetheless, one can understand psychosocial factors only by stepping outside the exclusively biological paradigm of contemporary medicine and taking a serious look at psychology and other social sciences.

Raz and Guindi explore placebos from the vantage point of current medical education. Fortunately, medical students who appreciate the notion of placebo in therapy may be able to build their careers on a foundation that encompasses mind-body interactions. Thus, future medical practitioners will greatly expand their knowledge base and clinical applications involving placebos.

\section{OTHER ASPECTS}

Placebos currently occupy a paradoxical position in both lay and scientific discourse, as a renewed interest in the mechanisms underlying various body-mind phenomena vies uneasily with skepticism of nonbiological explanations in medicine (1). An example of this tension was the powerful and conflicting set of reactions to a meta-analysis of clinical trials claiming that placebo effects are minimal or non-existent (44). 
Multiple researchers have critiqued many aspects of this controversial meta-analysis (45-48), and re-analyses of the data yielded findings of a "robust" placebo effect (49) setting off a flurry of rebuttals and debates (50-52).

Criticisms aside, this contentious meta-analysis is extremely telling in that the assumptions it makes about placebos are similar to those made by much of mainstream medicine. For example, it confuses confirmatory with exploratory explanations and treats meta-analyses of data from randomized clinical trials as one of the most authoritative ways of demonstrating effectiveness while it ignores experiments which demonstrate the mechanisms underlying placebo responses $(53,54)$. Indeed, epistemological issues explain one important source of difficulty for contemporary medicine in acknowledging placebo responses (3).

Contemporary medicine elides most aspects of the physician-patient encounter in its explanations of cure, but it also fosters an ideal - a fantasy in which biological disease entities thrive without the messiness of psychology, meaning, or culture. In this regard, Kihlstrom's allusion to the Star Trek Feinberger is most appropriate. The field of psychiatry provides an excellent example of this tendency.

While psychiatry used to engage with the social sciences for much of the 20th century $(55,56)$, over the past twenty-five years a biological paradigm has become more dominant, reducing psychological and psychiatric explanations of behavior to neurobiology (57). Thus for many professional leaders, including the scientific directors of the Canadian and U.S. national institutes of mental health, the future of psychiatry lies in its becoming "a clinical neuroscience discipline" (58). Such reductionism, however, often makes it difficult for clinicians to acknowledge, understand and treat patients whose "non-specific" symptoms deviate from textbook characterizations. This issue is especially poignant as efforts to revise the Diagnostic and Statistical Manual of Mental Disorders (DSM) will soon result in DSM-V $(59,60)$. Recent findings from psychological experiments and neuroimaging studies reveal that differences in cultural background and language mirror divergent cognitive styles (61). In addition, numerous experimental, clinical and ethnographic accounts reveal that beliefs and expectations are likely to have effects on the ways that people experience bodily sensations and symptoms (62, 63). Culturally-specific attributions of symptoms may shape a person's expectations so as to amplify experiences of particular somatic or psychological sensations, and it therefore seems that culture can frame symptoms (64).

We can illustrate how culture can shape biology.
Lactase, the enzyme necessary to digest milk, provides a good example into this process. While the majority of adult humans rarely produce lactase, descendants of populations which domesticated cattle and used milk as a central food source are more likely to carry a genetic variation allowing lactase to persist into adulthood (65, 66). Similarly, among Vietnamese and Cambodian patients in the U.S., researchers have described culturally-specific forms of panic $(67,68)$. Another example from Japanese culture draws on the societal value of aging females: menopausal women in Japan, are less likely to experience the hot flashes and night sweats that are widespread among older women in North America $(69,70)$. (Anthropologists have ruled out the possibility that these differences are due to eating more soy (i.e., ingesting chemicals that closely mimic the action of estrogen). Thus it is at least possible that this difference may have to do with the fact that Japanese culture promotes a different understanding of what it means to be an older woman and that the body is complying with this cultural expectation). A final example of cultural suggestion comes from the history of hypnosis which have changed in ways that reflect changing social expectations and mores (71): while the 18th century patients of Anton Mesmer convulsed violently as they felt animal magnetism racing through their bodies; those hypnotized by the Marquis de Puysegur entered a "sleep-walking" state; and JeanMartin Charcot's patients were and behaved as hysterics.

Indeed, the effect that culture has on behavior is consistent with our modern concept of suggestion - a powerful, psychological influence that affects individuals through their subjective beliefs and experiences. Our bodies seem to have a culture and a history (64). If we want to develop a medicine that is adequate to the needs of patients, we must acknowledge that beyond physiology, biology is a co-construct of cultural phenomena. Thus, our understanding of illness and cure must draw on the social as well as the life sciences.

\section{REFERENCES:}

1. Harrington A. The many meanings of the placebo effect: Where they came from, why they matter. Biosocieties. 2006;1:181-93.

2. Shapiro AK, Shapiro E. The Powerful Placebo: From Ancient Priest to Modern Physician. Baltimore, MD: Johns Hopkins University Press; 1997.

3. Harrington A. The placebo effect : an interdisciplinary exploration. Cambridge, Mass.: Harvard University Press; 1997.

4. Benedetti F. How the doctor's words affect the patient's brain. Evaluation \& the Health Professions. 2002 Dec;25(4):369-86.

5. Wager TD, Scott DJ, Zubieta J-K. Placebo effects on human $\{$ micro\}-opioid activity during pain. Proceedings of the National Academy of Sciences. 2007 June 26, 2007;104(26):11056-61.

6. Wager TD, Rilling JK, Smith EE, Sokolik A, Casey KL, 
Davidson RJ, et al. Placebo-Induced Changes in fMRI in the Anticipation and Experience of Pain. Science. 2004 February 20, 2004;303(5661):1162-7.

7. Kaptchuk TJ. The Placebo Effect in Alternative Medicine: Can the Performance of a Healing Ritual Have Clinical Significance? Annals of Internal Medicine. 2002;136:817.

8. Moerman DE, Jonas WB. Deconstructing the Placebo Effect and Finding the Meaning Response. Annals of Internal Medicine. 2002;136(6):471-6.

9. Wilce J, editor. Social and Cultural Lives of Immune Systems. New York: Routledge; 2003.

10. Csordas TJ. Elements of Charismatic Persuasion and Healing. Medical Anthropology Quarterly. 1988;2:121-42.

11. Kirmayer LJ. The cultural diversity of healing: meaning, metaphor and mechanism. Br Med Bull. 2004;69:33-48.

12. Jacob JR. Robert Boyle and Subversive Religion in the Early Restoration. Albion: A Quarterly Journal Concerned with British Studies. 1974;6(4):275-93.

13. Alexander F, Selesnick S. The History of Psychiatry: An Evaluation of Psychiatric Thought and Practice from Prehistoric Time to the Present. New York: Harper \& Row Publishers; 1966.

14. Laurence RM. Primitive Psychotherapy and Quackery. Boston: Houghton Mifflin; 1910.

15. Bromberg W. Man above Humanity : A History of Psychotherapy. Philadelphia: Lippincott; 1954.

16. Weinberg S. Dreams of a Final Theory: The Search for the Fundamental Laws of Nature. New York: Pantheon Books; 1992.

17. Raz A, Fan J, Posner MI. Hypnotic suggestion reduces conflict in the human brain. Proc Natl Acad Sci U S A. 2005 Jul 12;102(28):9978-83.

18. Raz A, Shapiro T. Hypnosis and Neuroscience: A Cross Talk Between Clinical and Cognitive Research. Arch Gen Psychiatry. 2002 January 1, 2002;59(1):85-90.

19. Raz A, Shapiro T, Fan J, Posner MI. Hypnotic Suggestion and the Modulation of Stroop Interference. Arch Gen Psychiatry. 2002 December 1, 2002;59(12):1155-61.

20. Moerman DE. Meaning, medicine, and the "placebo effect". Cambridge, U.K. ; New York: Cambridge University Press; 2002.

21. Price DD, Finniss DG, Benedetti F. A Comprehensive Review of the Placebo Effect: Recent Advances and Current Thought. Annu Rev Psychol. 2007 Jun 5.

22. Sherman R, Hickner J. Academic physicians use placebos in clinical practice and believe in the mind-body connection. J Gen Intern Med. 2008 Jan;23(1):7-10.

23. Goldberg RJ, Leigh H, Quinlan D. The current status of placebo in hospital practice. General Hospital Psychiatry. 1979;1(3):196-201.

24. Goodwin JS, Goodwin JM, Vogel AV. Knowledge and Use of Placebos by House Officers and Nurses. Annals of Internal Medicine. 1979;91(1):106.

25. Gray G, Flynn P. A survey of placebo use in a general hospital. General Hospital Psychiatry. 1981;3(3):199-203.

26. Ernst E, Abbot NC. Placebos in clinical practice: results of a survey of nurses. Perfusion. 1997;10:128-30.

27. Hrobjartsson A, Norup M. The Use of Placebo Interventions in Medical Practice--A National Questionnaire Survey of Danish Clinicians. Eval Health Prof. 2003 June 1, 2003;26(2):153-65.

28. Nitzan U, Lichtenberg P. Questionnaire survey on use of placebo. BMJ. 2004 October 23, 2004;329(7472):944-6.

29. Rothman DJ. Strangers at the bedside: a history of how law and bioethics transformed medical decision making. New York: Aldine de Gruyter; 2003.

30. Spiro H. Clinical Reflections on the Placebo Phenomenon. In: Harrington A, editor. The Placebo Effect, An Interdisciplinary
Exploration. Cambridge, MA: Harvard University Press; 1997.

31. Beecher HK. The powerful placebo. J Am Med Assoc. 1955;159(17):1602-6.

32. Beecher HK. Ethics and Clinical Research. New England Journal of Medicine. 1966;274:1354-60.

33. Kelly A. Research and the Subject: The Practice of Informed Consent.

34. Benedetti F, Lanotte M, Lopiano L, Colloca L. When words are painful: Unraveling the mechanisms of the nocebo effect. Neuroscience. 2007;147:260-71.

35. Hahn RA. The Nocebo Phenomenon: Concept, Evidence, and Implications for Public Health. Preventive Medicine. 1997;26(5):607-11.

36. Barrett B, Muller D, Rakel D, Rabago D, Marchand L, Scheder J. Placebo, meaning, and health. Perspect Biol Med. 2006;49(2):178-98.

37. De Amici D, Klersy C, Ramajoli F, Brustia L, Politi P. Impact of the Hawthorne Effect in a Longitudinal Clinical Study The Case of Anesthesia. Controlled Clinical Trials. 2000;21(2):103-14.

38. Smith SM, Schroeder K, Fahey T. Over-the-counter medications for acute cough in children and adults in ambulatory settings. Cochrane Database Syst Rev. 2008(1):CD001831.

39. Wingert WE, Mundy LA, Collins GL, Chmara ES. Possible role of pseudoephedrine and other over-the-counter cold medications in the deaths of very young children. J Forensic Sci. 2007;52(2):487-90.

40. Paul IM, Beiler J, McMonagle A, Shaffer ML, Duda L, Berlin CM. Effect of honey, dextromethorphan, and no treatment on nocturnal cough and sleep quality for coughing children and their parents. Arch Pediatr Adolesc Med. 2007;161(12):1140-6.

41. Anbar RD. Hypnosis: An important multifaceted therapy. The Journal of Pediatrics. 2006;149(4):438-9.

42. Good B. How medicine constructs its objects. Medicine, Rationality, and Experience: An Anthropological Perspective. Cambridge, UK: Cambridge University Press; 1994.

43. Luhrmann TM. Of two minds : the growing disorder in American psychiatry. New York: Knopf.; 2000.

44. Hrobjartsson A, Gotzsche PC. Is the placebo powerless? An analysis of clinical trials comparing placebo with no treatment. New England Journal of Medicine. 2001 May 24;344(21):1594602.

45. Greene PJ, Wayne PM, Kerr CE, Weiger WA, Jacobson E, Goldman P, et al. The powerful placebo: doubting the doubters. Adv Mind Body Med. 2001;17(4):298-307; discussion 12-8.

46. Kirsch I, Scoboria A. Apples, oranges, and placebos: heterogeneity in a meta-analysis of placebo effects. Adv Mind Body Med. 2001;17(4):307-9.

47. Spiegel D, Kraemer H, Carlson RW. Is the placebo powerless. N Engl J Med. 2001;345:1276.

48. Price DD, Finniss DG, Benedetti F. A comprehensive review of the placebo effect: recent advances and current thought. Annu Rev Psychol. 2008;59:565-90.

49. Wampold BE, Minami T, Tierney SC, Baskin TW, Bhati KS. The placebo is powerful: estimating placebo effects in medicine and psychotherapy from randomized clinical trials. J Clin Psychol. 2005;61(7):835-54.

50. Hrobjartsson A, Gotzsche PC. Is the placebo powerless? Update of a systematic review with 52 new randomized trials comparing placebo with no treatment. Journal of Internal Medicine. 2004;256:91-100.

51. Hrobjartsson A, Gotzsche PC. Powerful spin in the conclusion of Wampold et al.'s re-analysis of placebo versus no-treatment trials despite similar results as in original review. J Clin Psychol. 2007;63(4):373-7.

52. Wampold BE, Imel ZE, Minami T. The placebo effect: "Relatively large" and "robust" enough to survive another 
assault. Journal of Clinical Psychology. 2007;63(4):401-3.

53. Kaptchuk TJ, Kelley JM, Conboy LA, Davis RB, Kerr CE, Jacobson EE, et al. Components of placebo effect: randomised controlled trial in patients with irritable bowel syndrome. British Medical Journal. 2008;336(7651):999.

54. Kaptchuk TJ, Stason WB, Davis RB, Legedza ART, Schnyer $\mathrm{RN}$, Kerr CE, et al. Sham device $\mathrm{v}$ inert pill: randomised controlled trial of two placebo treatments. BMJ: British Medical Journal. 2006;332:391.

55. Luhrmann TM. Of two minds: the growing disorder in American psychiatry. New York: Knopf; 2000.

56. Shorter E. A History of Psychiatry : From the Era of the Asylum to the Age of Prozac. New York: Wiley; 1998.

57. Gold I, Stoljar D. A neuron doctrine in the philosophy of neuroscience. Behavioral and Brain Sciences. 1999;22(05):80930.

58. Insel TR, Quirion R. Psychiatry as a Clinical Neuroscience Discipline. JAMA. 2005;294(17):2221.

59. Fink M, Taylor MA. Issues for DSM-V: the medical diagnostic model. Am J Psychiatry. 2008 Jul;165(7):799.

60. Krahn LE, Bostwick JM, Stonnington CM. Looking Toward DSM-V: Should Factitious Disorder Become a Subtype of Somatoform Disorder? Psychosomatics. 2008 JulAug;49(4):277-82.

61. Han S, Northoff G. Culture-sensitive neural substrates of human cognition: a transcultural neuroimaging approach. Nat Rev Neurosci. 2008;9(8):646-54.
62. Kirmayer LJ, Sartorius N. Cultural Models and Somatic Syndromes. Psychosom Med. 2007;69:832-40.

63. Hinton DE, Howes D, Kirmayer LJ. Toward a medical anthropology of sensations: definitions and research agenda. Transcult Psychiatry. 2008;45(2):142-62.

64. Harrington A. The cure within : a history of mind-body medicine. 1st ed. New York: W.W. Norton; 2008.

65. Beja-Pereira A, Luikart G, England PR, Bradley DG, Jann OC, Bertorelle G, et al. Gene-culture coevolution between cattle milk protein genes and human lactase genes. Nature Genetics. 2003;35(4):311-3

66. Durham WH. Coevolution: Genes, Culture, and Human Diversity. Stanford, CA: Stanford University Press; 1991.

67. Hinton D, Um K, Ba P. Kyol Goeu ('Wind Overload') Part I: A Cultural Syndrome of Orthostatic Panic among Khmer Refugees. Transcultural Psychiatry. 2001;38:403.

68. Hinton DE, Hinton L, Tran M, Nguyen M, Nguyen L, Hsia C, et al. Orthostatic panic attacks among Vietnamese refugees. Transcult Psychiatry. 2007;44(4):515-44.

69. Lock M, Kaufert P. Menopause, local biologies, and cultures of aging. American Journal of Human Biology. 2001;13(4):494504.

70. Lock MM. Encounters with aging : mythologies of menopause in Japan and North America: University of California Press; 1993.

71. Gauld A. A History of Hypnotism. Cambridge, UK: Cambridge University Press; 1992.

Amir Raz Ph.D., ABPH, is the Canada Research Chair in the Cognitive Neuroscience of Attention at McGill University and the Jewish General Hospital. He holds faculty positions in the departments of Psychiatry, Neurology \& Neurosurgery, and Psychology. He received his Ph.D. in Brain Science from the Interdisciplinary Center for Neural Computation at the Hebrew University of Jerusalem. Prior to his recent transition to McGill, he held academic positions at the Weill Medical College of Cornell University and the Columbia Medical School.

Eugene Raikhel is a medical anthropologist and postdoctoral fellow in the Division of Social and Transcultural Psychiatry at McGill University. He has conducted research on addiction and its treatment in contemporary Russia and is currently developing an ethnographic project on the use of placebos in clinical practice.

Ran D. Anbar is Professor of Pediatrics and Medicine at the SUNY Upstate Medical University, where he serves as Director of the Pediatric Pulmonary and Cystic Fibrosis Center. He is a Fellow of the American Academy of Pediatrics, and an Approved consultant for the American Society of Clinical Hypnosis. He has published extensively about asthma, cystic fibrosis, and clinical hypnosis. He has been principal investigator of over 30 randomized placebo-controlled clinical trials, and has served as reviewer of research publications for medical journals, research grant reviewer and dissertation defense committee member. 